\title{
Intramedullary mature teratoma of the conus medullaris
}

\author{
Kadir Oktay, Nuri Eralp Cetinalpp, Kerem Mazhar Ozsoy'1, Semih Kivanc Olguner, Mustafa Emre Sarac², \\ Sakir Berat Vural ${ }^{1}$ \\ Department of Neurosurgery, Mehmet Akif Inan Training and Research Hospital, Sanliurfa, ${ }^{1}$ Department of Neurosurgery, School of Medicine, \\ Cukurova University, ${ }^{2}$ Department of Neurosurgery, Ceyhan State Hospital, Adana, Turkey
}

\section{ABSTRACT}

Teratoma is a tumor that derivatives from all three primitive germ layers and spinal intramedullary teratomas are very rare lesions. The primary treatment modality for these tumors is surgical resection, and total resection should be the aim. However, subtotal resection is a valid alternative to prevent traumatizing adjacent functional neural tissue. In this report, we presented a case of a 12-year-old male patient with spinal teratoma of the conus medullaris. We describe the presentation, evaluation, and treatment of this rare disease.

Key words: Conus medullaris, intramedullary teratoma, mature teratoma, spinal tumor

\section{Introduction}

Teratomas are tumors that typically, but not always contain all three germ cell layers ectoderm, mesoderm, and endoderm. Teratomas are classified as mature, immature, and malignant based on the degree of differentiation. ${ }^{[1]}$ Spinal teratoma is an uncommon diagnosis. These tumors usually develop in the sacrococcygeal region and the infancy period. Intramedullary teratomas are even less common. These lesions can occur throughout the spinal canal, but there is a thoracic and lumbar predominance among reported cases with the conus medullaris region being the most frequent. ${ }^{[1,2]}$

\section{Case Report}

A 12-year-old boy was referred to our hospital with a 2 months history of back pain and 1-week history

\section{Address for correspondence:}

Dr. Kadir Oktay, Department of Neurosurgery, Mehmet Akif Inan

Training and Research Hospital, Sanliurfa, Turkey.

E-mail: drkadiroktay@hotmail.com

\begin{tabular}{|l|l|}
\hline \multicolumn{2}{|c|}{ Access this article online } \\
\hline Quick Response Code: & Website: \\
\hline & www.ruralneuropractice.com \\
\cline { 2 - 3 } & \\
\hline & \\
\hline
\end{tabular}

of bilateral leg weakness, urinary incontinence, and constipation. On physical examination; he had no gross motor deficit but bilateral numbness in his legs. He had no cutaneous abnormalities, and there was no evidence of dysraphism. Lumbosacral spine magnetic resonance imaging revealed a well-delineated, intramedullary, $2 \mathrm{~cm} \times 4 \mathrm{~cm}$ mass at the L1-2 levels of the lumbar spine. The mass was hyperintense in all sequences, and it was containing a hypointense lesion in the central zone. The lesion could not be separated from the conus medullaris [Figure 1].

The patient underwent an emergent surgery. The operation was performed under a surgical microscope with the assistance of intraoperative neurogenic monitoring evoked potentials. Reconstructive laminoplasties were performed to the L1 and L2 vertebrae. Dura mater was opened and the mass filling the spinal canal was detected. A midline incision was performed at the conus medullaris level, and a creamy, yellow-white, mucoid substance was discharged. Subsequent to the evacuation of the tumor's content, calcified solid component, and capsule was resected. However, gross total resection

This is an open access article distributed under the terms of the Creative Commons Attribution-NonCommercial-ShareAlike 3.0 License, which allows others to remix, tweak, and build upon the work non-commercially, as long as the author is credited and the new creations are licensed under the identical terms.

For reprints contact: reprints@medknow.com

How to cite this article: Oktay K, Cetinalp NE, Ozsoy KM, Olguner SK, Sarac ME, Vural SB. Intramedullary mature teratoma of the conus medullaris. J Neurosci Rural Pract 2016;7:305-7. 


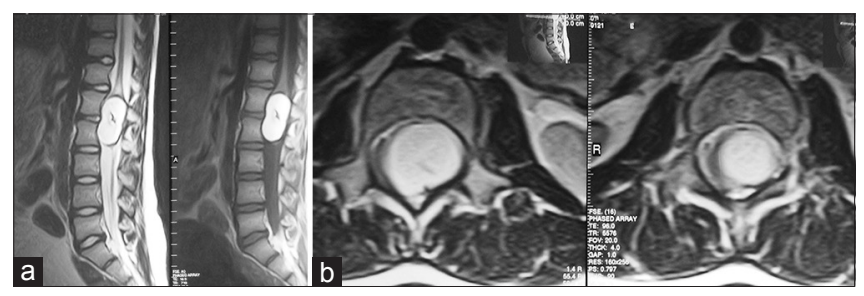

Figure 1: Magnetic resonance imaging of lumbar spine; (a) sagittal T2-weighted and (b) axial T2-weighted images showing a well-delineated, intramedullary, $2 \mathrm{~cm} \times 4 \mathrm{~cm}$ mass at the L1-2 levels of the lumbar spine

could not be performed because of the tenacious adhesions of the tumor to the adjacent parenchyma. Approximately, 95\% of the tumor was resected. After removal of the tumor, dura mater and L1 and L2 vertebrae were reconstructed. The histopathological examination of the mass revealed a mature teratoma with fully differentiated components. There was no evidence of immature and malignant components [Figure 2]. The patient had an uneventful postoperative course and his severe back pain and bilateral leg weakness improved after the surgery. Urinary incontinence and constipation complaints are improved in 2 weeks after surgery. Now, as 1 month after surgery, the patient has no reported recurrent symptoms.

\section{Discussion}

Spinal teratomas are uncommon lesions. They account for only $0.2-0.5 \%$ of all spinal cord tumors. ${ }^{[1,3]}$ They can be intramedullary or extramedullary. Associated anomalies such as metameric cutaneous lesions, sinus tracts, neural tube defects or split cord malformations may be present. ${ }^{[2,4]}$

The current classification states that a teratoma is a tumor that composed of derivatives from all 3 primitive germ layers. Histologically, these lesions are divided into three categories; mature, immature, and malignant. Mature and immature teratomas may be considered benign, especially if treated early. Mature teratomas contain components that are fully differentiated. Immature lesions typically contain fetal tissue. Malignant teratomas are named for the presence of the malignant germ cell layer component. It is important to study the specimen completely because benign and malignant elements can be present simultaneously. ${ }^{[5]}$

Preoperative imaging techniques are not useful for the exact diagnosis of intramedullary teratomas. Magnetic resonance imaging is the most valuable diagnostic technique but, even so it cannot determine with certainty the differential diagnosis between

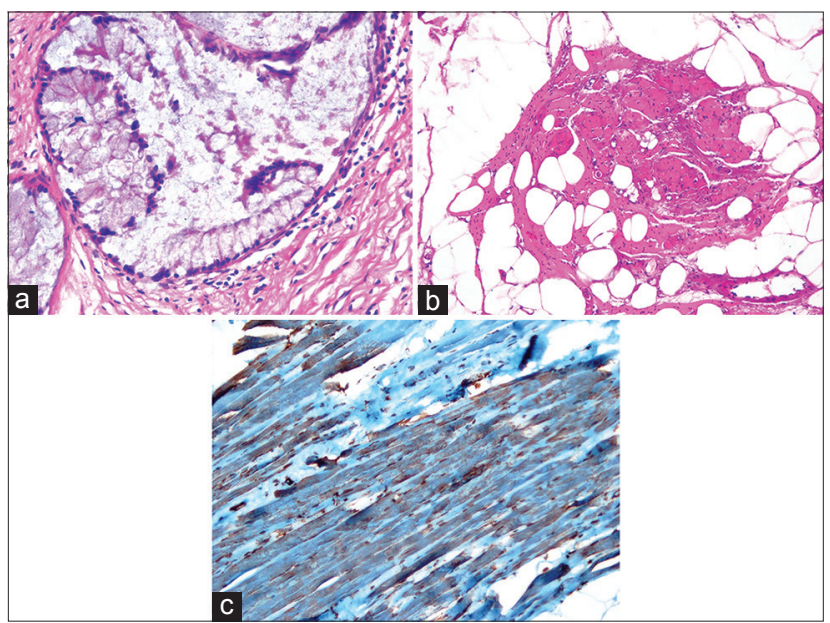

Figure 2: (a) Photomicrograph $(\mathrm{H}$ and $\mathrm{E}, \times 40)$ showing connective tissue containing mucinous epithelium (b) photomicrograph ( $\mathrm{H}$ and $\mathrm{E}$, $\times 20)$ showing adipose tissue containing mature muscle cells (c) photomicrograph $(\mathrm{IHC}, \times 40)$ showing smooth muscle cells reacted positively with actin

teratoma and other intramedullary lesions. Definitive diagnosis is only possible with histopathological examination..$^{[1,6]}$

The primary treatment for teratomas is surgery, and total surgical resection of the tumors should be the aim of these operations. However, as in our case gross total resection may not be possible in every operation. In a literature review made by Poeze et al., it was found that intramedullary tumors could be completely removed only in $61.8 \%$ of the reported cases. ${ }^{[1]}$

Application of intraoperative electrophysiologic monitoring is important in these operations, and it is important to resect tumor as extensive as possible according to intraoperative electrophysiologic monitoring findings. Removal of the tumor should be stopped when the neurological function is at risk due to the tenacious adhesions of the tumor to the adjacent parenchyma. Recurrence rates depend on the histopathological characteristics of the tumors. Recurrences were found to be more commonly encountered with immature and malignant teratomas. Nonetheless symptomatic recurrence rates of mature teratomas were very low even in subtotal resections. ${ }^{[1,7,8]}$ Radiotherapy is an adjuvant treatment modality that should be indicated when the tumors contain malignant components. However, adjuvant radiotherapy is not recommended for benign teratomas, and there is not any role of adjuvant chemotheraphy in the treatment of spinal teratomas. ${ }^{[6-8]}$

\section{Financial support and sponsorship} Nil. 


\section{Conflicts of interest}

There are no conflicts of interest.

\section{References}

1. Poeze M, Herpers MJ, Tjandra B, Freling G, Beuls EA. Intramedullary spinal teratoma presenting with urinary retention: Case report and review of the literature. Neurosurgery 1999;45:379-85.

2. Sharma MC, Aggarwal M, Ralte AM, Vaishya V, Suri A, Gupta V, et al. Clinicopathological study of spinal teratomas. A series of 10 case. J Neurosurg Sci 2003;47:95-100.

3. Nonomura Y, Miyamoto K, Wada E, Hosoe H, Nishimoto H, Ogura H, et al. Intramedullary teratoma of the spine: Report of two adult cases.
Spinal Cord 2002;40:40-3.

4. Mut M, Shaffrey ME, Bourne TD, Jagannathan J, Shaffrey CI. Unusual presentation of an adult intramedullary spinal teratoma with diplomyelia. Surg Neurol 2007;67:190-4.

5. Alden TD. Spine tumors in children. In: Winn HR, editor. Youman's Neurological Surgery. $6^{\text {th }}$ ed. Philadelphia: Saunders; 2012. p. 2271-8.

6. Allsopp G, Sgouros S, Barber P, Walsh AR. Spinal teratoma: Is there a place for adjuvant treatment? Two cases and a review of the literature. $\mathrm{Br}$ J Neurosurg 2000;14:482-8.

7. Ak H, Ulu MO, Sar M, Albayram S, Aydin S, Uzan M. Adult intramedullary mature teratoma of the spinal cord: Review of the literature illustrated with an unusual example. Acta Neurochir (Wien) 2006;148:663-9.

8. Kahilogullari G, Erdem A, Heper AO, Erden E. Intramedullary mature cystic teratoma of the conus medullaris. A case report. J Neurosurg Sci 2006;50:55-8. 